\title{
Underspecified Dreams of Parts and Wholes
}

Matthew Fuller 
Ecological thought emphasises the interplay of part-whole relations, those of parts, for instance a plant, a species, operating in a non-unified whole. Ecologies are wholes that are never complete. They emerge out of the interactions of a multitude of processes and entities and operate and are acted in at multiple scales. This complex relation between the part and the whole is an aspect of what makes ecologies open to being thought of as systems. It also allows us to think about ecologies in abstract terms, as something sharing qualities with other non-totalising systems such as media.

This condition of interplay between parts and wholes is something that characterises aesthetic work, the relation of a musical phrase to that of the whole symphony; the particular style of movement of a character in a computer game to that of the capacities of others; the particular inflection of design of a door in its relation of analogy and differentiation to the other objects in a room, the treatment of its surfaces; and its keying in to the design of the building as a whole in architecture. Music, games and buildings, as different media systems (if we can take that term broadly) each have their own characteristic ways of addressing or composing an idea of the general: how they act to compose the world in terms of uniformity, differentiation, and co-composition. The relation between the specific and the general can in turn be seen as a translation of the part-whole figuration. To take a particular example, something as everyday as a bridge plays out a relation between the specific and the general.

When you are thinking about design at the infrastructural level you must resist thinking from the basis of precise cases. For instance, in designing a bridge, you don't bring it together on the basis of the particular vehicles that travel over it, this specific car, or that individual truck. You certainly don't think about a particular group of people driving over it whilst singing a certain song on a certain day several years hence, or design the rumbling of the road surface in contact with the tyres to assuage the distress of a particular group of sheep who might be on their way to the slaughterhouse in the back of a lorry. A bridge deals with the general, not with the specific.

A bridge is designed in relation to certain generic standards such as those of construction strength, the habitual or novel use of form and materials, expectations of use characterised at a statistically developed level. It implies a certain universality of travel. At the same time though, it may react to local conditions, propose new stylistic or structural concerns, articulate the relation between what is under and what is above, spread the expe- 
${ }^{1}$ For a story about bridges, see Winner (1999). For a critical response, see Joerges (1999).
${ }^{2}$ For a discussion of platforms in digital media see Goriunova (2013). rience of movement across it, suture landscapes, economies or languages, and do many other things.

Bridge design can be used of course for a certain amount of disruptive activity. This is perhaps why bridges are so often targeted in conflicts, as means of disrupting supplies and movements. Bridges are also a classic artefact in claiming a politics of technology. They may act as a force of blockage as much as one of conjunction ${ }^{1}$.

The urban theorist Keller Easterling writes about such things as part of her discussion of a politics of infrastructure (Easterling, 2014). Standards, road typologies, the size of physical interfaces to banking devices, ID cards, all integrate, amongst their universalism, a kind of uniformity. It is the specific texture and tonality of this uniformity that engenders much of their politics. This politics is not to be simply understood as one of prohibitions, mobilisations, commands and so on - a model drawn from the military - but rather one of establishing the means by which things gain the conditions of becoming possible. Here, design thinks about itself in the role of producing the raw materials for a further stage of change. Establishing the grammar of such change is a key stakes of power in the present era.

Perhaps anticipating this condition, and also seeing it played out through a paternalistic modernism of buildings with their modes of use being overly-prescribed in advance, Gordon Pask (1969) talked about a cybernetically-inspired ethics of design in terms of what he called "Underspecification". That is that things should be made in order that their function can be reinvented, coupled with other things, that they do not pre-empt the future. A bridge in this sense is also then a platform, a set of conditions for things to happen ${ }^{2}$. Underspecification is a conceptually advanced form of modesty for architecture, the idea that it is to make entities out of which other things will be composed. It aims to allow for the relation between the specific and the general to remain unfinished.

The extent and affordances of the underspecification of objects and systems is an important condition for contemporary design in an era of digitalisation, expanded forms of materiality and of globalization. Easterling's reflections are particularly useful for a consideration of the latter, as standard objects proliferate as means of implementing and maintaining conjunction across the globe. Here, she identifies a nuanced micropolitics of the artifact, and of norms and the interplay between them to create a grammar for global assemblages. There is a sense in which parts become 
${ }^{3}$ See for instance in the journal Computational Culture (http:// www.computationalculture.net/). simply subsets of wholes, rather than wholes arising from the interplay of parts, where the general conditions the particular - leading to the danger of a loss of variety, and of a politics of homogeneity arising from the simple unfolding of pre-formatted parts.

Modular forms may also open up possibilities for recombination and generativity, as in the ideal of the sandbox - as found for instance in games and in learning. However, underspecification may also function as a technique of absorbing the unexpected emergence of otherwise irresolvable social forms, as a form of preemptive architecture of crumple-zones.

That is to say that the particular forms in which an underspecified design plays out, in terms of its texture, what it blocks, combines with, draws out, or inspires have a fundamentally political level, but one that is often articulated as being solely technical in nature: when the technical is understood to be ostensibly neutral. In particular we see this in the "facilitation" offered by software and by computational infrastructure, of the everyday, of governance and of selfhood. The expanded forms of materialization that constitute the remarkable way in which computational forms have been woven into and now substantially constitute the condition of contemporary culture.

In a sense, there is an argument that the position that software development is "simply technical" works, in that it is an argument that itself is truly underspecified. It thus gives room for an abundance of invention, manipulation and counter-currents of use, since those aspects of the work that were seen to be non-technical are not attended too.

At the same time, there is an increasing attention to the modes of cultural operation of things such as algorithms, data structures, file formats, databases, interfaces, protocols, data security and so on that constitute the everyday technical material of software developers ${ }^{3}$. Here, for the purposes of cultural invention, or for understanding such materials in political terms, it is important that the recognition of their materiality is expanded beyond the simple replication of their technical description.

The scholar Ben Kafka notes something similar in relation to the question of paperwork and the files characteristic of bureaucracy, a close description of their agency, must be accompanied by a recognition of their integration with and incitement of neurotic and desiring activity (Kafka, 2012). Indeed, this is so much the case, that, as with the "simply technical", underspecification per se can only be a description of a tendency. Attempts 
to reduce things to a purely functionalist level of description can indeed occur - as in border crossings, or other zones where there is tight, and highly tense, reduction of things to a stable script. These specimens require an enormous amount of supplementary equipment and work to hold such a condition in place.

The extended debates amongst developers about whether the fifth version of HTML (the mark-up and programming language for the web, that now includes vastly expanded provision for the creation of apps, and for video, amongst other things) should include a native mechanism for so-called "Digital Rights Management" show that the question of what and who a technology is for, and what implications it has for the circulation of culture, even if only in well-established discursive forms such as the discussion of that curious formula "Intellectual Property", have at least some degree of traction. In this case, other interests prevailed.

In the last chapter of her book, Easterling suggests that a certain kind of cunning with technology and with standards is required in order to work politically in the present. To put this differently, to work with the agency of the particular characteristics of certain kinds of code, interface, screen, is part of the art of the contemporary. And such an art is articulated differently by multiple actors: regulators, inventors, user experience designers, companies, hackers, international standards bodies. To make such an incomplete list of actors is to suggest an ecology of part-whole relations around and constituted in a technology. Alongside these figures, we can array others who specifically work to maintain qualities of underspecification, even in the most totalised of medial systems.

One of the means of rendering even the most totalising system into a state of underspecification is to submit it to the imagination - and here Kafka's injunction to recognise medial materiality in relation to questions of psychic conditioning and desire comes to the fore. Here too, the historic role of art, even if it has been one that has been partially swapped out for something tidier and more convenient, is worth attending to.

The Russian Futurist Velimir Khlebnikov is the author of a myriad of brilliant texts; a visionary, linguist and geographer, he had the great fortune to be the author of "The Radio of the Future" (Khlebnikov, 1921), a prognosis for media systems that thrills with its capacity to overstep the bounds of the foreseeable, the standardized and the normative. At the same time, the text imagines a new deliriously inventive form of universality, or space of general communication. Russian Futurism took the 
future to not simply mean the tense that comes after the present, but the condition in which becoming becomes. From this position they were able to enter into their present from the point of view that was no longer what it was, since it had already entered into becoming. An understanding of materiality, whether that was of words, languages, paint, clothing, alcohol, and technology, was coupled with this imagination; a vivid materiality that specified the hitherto unspeakable, rendering the world open to the play of delight and invention and of dreams.

A related opening up of technology to the imagination can be read in feminist work that rejects the convention of acquiescence to an imagined nature. The 1970s writing of Shulamith Firestone, particularly the closing chapters of her "Dialectic of Sex" (Firestone, 1970), or the recent Xenofeminist manifesto (Laboria Cuboniks, 2015), and certain currents within Sadie Plant's “Zeroes and Ones" (Plant, 1995) work this seam in which the cantankerous and cretinising part-whole relations of gender standardisation are opened up through, as Firestone puts it, an integration of the poetic and the technological. Feminism of this kind is an immense resource in thinking through designing in the era of digitalization, expanded forms of materiality and globalization since it is very familiar with the relentless labour of challenging the supposedly natural and organic nature of certain ways of reducing people to parts, the overspecification of relations and of the immense and intimate labour of standardisation.

Whilst it shares with art an openness to reinvention and dream, such feminist work is reasonably suspicious of making yet another call to dream in order to reconstitute the world, for this is already common knowledge, and the world is an accretion of such dreams or of desires taken for reality. Living in a time when a technical disposition to openness, also provides a form of capture, we know that certain dreams, namely nightmares, are of great preponderance. In this condition, the question of the composition of the relation between the specific and the general becomes one in which a certain cunning is required in order to remain underspecified, with a certain tensile relation to becoming. 


\section{Matthew Fuller}

Professor of Cultural Studies and Director of

the Centre for Cultural Studies, Goldsmiths, University of London. He is co-author with Andrew Goffey of 'Evil Media' (MIT), Editor of 'Software Studies, a lexicon' (MIT), author of 'Media Ecologies' (MIT) and co-editor of the journal Computational Culture.

E-mail:m.fuller@gold.ac.uk 


\section{References}

Easterling, K., 2014. Extrastatecraft, the power of infrastructure space. London: Verso.

Firestone, S., 1970. The Dialectic of Sex. The case for feminist revolution. New York: William Morrow and Company.

Goriunova, O., 2013. Art Platforms and cultural production on the internet. London: Routledge.

Joerges, B., 1999. Do Politics Have Artefacts? Social Studies of Science, 29(3), pp.411-431.

Kafka, B., 2012. The Demon of Writing: powers and failures of paperwork. New York: Zone Books.

Khlebnikov, V., 1921. The Radio of the Future. In: Ch. Douglas, ed. 1987. Collected Works of Velimir Khlebnikor, 1: Letters and Theoretical Writings. Cambridge: Harvard University Press, pp.392-396.

Laboria Cuboniks, 2015. The Xenofeminist Manifesto. [online] Available at: <http://laboriacuboniks.net/> [Accessed 27 May 2016].

Pask, G., 1969. The Architectural Relevance of Cybernetics. Architectural Design, September issue, pp.494-496

Plant, S., 1995. Zeroes and Ones, digital women and the new technoculture. London: Fourth Estate.

Winner, L., 1999. Do Artifacts Have Politics? In: D. Mackenzie, J. Wajcman, eds. 1999. The Social Shaping of Technology. 2nd ed. London: Open University Press. 